\title{
Atrial and placental melanoma metastasis: a case report and literature review
} Pradeep Lakshminarayana*1, Sarah Danson ${ }^{1}$, Kim Suvarna ${ }^{2}$ and Barry Hancock ${ }^{1}$

Address: ${ }^{1}$ Department of Clinical Oncology, Weston Park Hospital, Whitham Road, Sheffield, S10 2SJ, UK and ${ }^{2}$ Department of Histopathology, Northern General Hospital, Herries Road, Sheffield, S5 7AU, UK

Email: Pradeep Lakshminarayana* - drpradeephl@yahoo.co.uk; Sarah Danson - S.Danson@sheffield.ac.uk;

Kim Suvarna - Kim.Suvarna@sth.ac.uk; Barry Hancock - b.w.hancock@sheffield.ac.uk

* Corresponding author

Published: I4 May 2007

Journal of Medical Case Reports 2007, I:2I doi:I0.1 I86/I752-1947-I-2I

Received: 7 April 2007

Accepted: 14 May 2007

(C) 2007 Lakshminarayana et al; licensee BioMed Central Ltd.

This is an Open Access article distributed under the terms of the Creative Commons Attribution License (http://creativecommons.org/licenses/by/2.0), which permits unrestricted use, distribution, and reproduction in any medium, provided the original work is properly cited.

\begin{abstract}
Malignant melanoma can metastasize to virtually any organ of the body. The aggressiveness is determined by the primary site, depth of dermal invasion, presence or absence of ulceration, lymphovascular infiltration and regional lymph node involvement. We report a case of a pregnant woman with a previous history of stage 3 melanoma who presented with cardiac metastasis and placental melanoma infiltration. A review of literature on cardiac and placental involvement of melanoma is also provided.
\end{abstract}

\section{Background}

Malignant melanoma is considered to be a highly aggressive cancer. Post mortem studies have shown that melanoma can metastasize to any organ of the body, with $50 \%$ of the patients found to have cardiac involvement [1]. However only $2 \%$ of patients with metastatic melanoma to the heart are diagnosed antemortem [2], as most patients do not have any cardiac symptoms. Melanoma is also unique in that it is the most common cancer to metastasize to the placenta [3].

We report a pregnant woman with invasive melanoma who presented with metastasis in the right atrium and placental melanoma infiltration. The balance of surgery, chemotherapy and obstetric management in this case is challenging.

\section{Case report}

A 32 year old woman, initially presented at the age of 27 with stage 3 malignant melanoma. The patient underwent wide local excision of a $1.76 \mathrm{~mm}$ Breslow thickness melanoma from the right thigh and shortly afterwards was found to have a mass in the right groin. She underwent right inguinal block dissection, with 2 of 6 lymph nodes positive for melanoma. CT scan showed no evidence of other disease sites. The patient had adjuvant high dose interferon $\left(20 \mathrm{MU} / \mathrm{m}^{2} / \mathrm{d}\right.$ IV 5 days/wk $\times 4$ weeks followed by $10 \mathrm{MU} / \mathrm{m}^{2} \mathrm{SC}$ thrice weekly $\times 48$ weeks) which was discontinued after nearly 7 months due to persistent neutropenia.

When aged 31 and 19 weeks pregnant, the patient noticed a mass beneath her jaw consistent with right submandibular lymph gland enlargement and had exertional dypsnoea. A CT scan revealed a pericardial effusion of $1 \mathrm{~cm}$ depth. A transthoracic echocardiogram showed a right 
atrial mass prolapsing through the tricuspid valve with good preservation of ventricular function.

An MRI scan of the heart confirmed the mass to be more extensive measuring $8 \mathrm{~cm}$ in size and extending into the superior vena cava (fig 1). An echocardiogram guided biopsy of the mass (fig $2 \mathrm{~A}$ ) revealed necrotic tumour with associated thrombus and adjacent normal myocardium. The viable tumour was composed of moderately pleomorphic epitheliod melanocyes (S100/HMB45 positive) with enlarged pleomorphic nuclei and prominent nucleoli.

The patient was keen to continue with pregnancy and after careful consideration was commenced on palliative chemotherapy with dacarbazine ( $800 \mathrm{mg} / \mathrm{m}^{2}$ IV every 3 weeks). The decision was to deliver the baby early by elective Caesarean section at 34 weeks of gestation considering the risk of sudden cardiac death of the mother, which would likely be associated with fetal demise. After 2 cycles of dacarbazine, an echocardiogram showed that the atrial mass was smaller.

However an emergency Caesarean section was performed at 31 weeks gestation because of ante-partum haemorrhage. The baby delivered weighed $1.5 \mathrm{~kg}$ with no signifi-

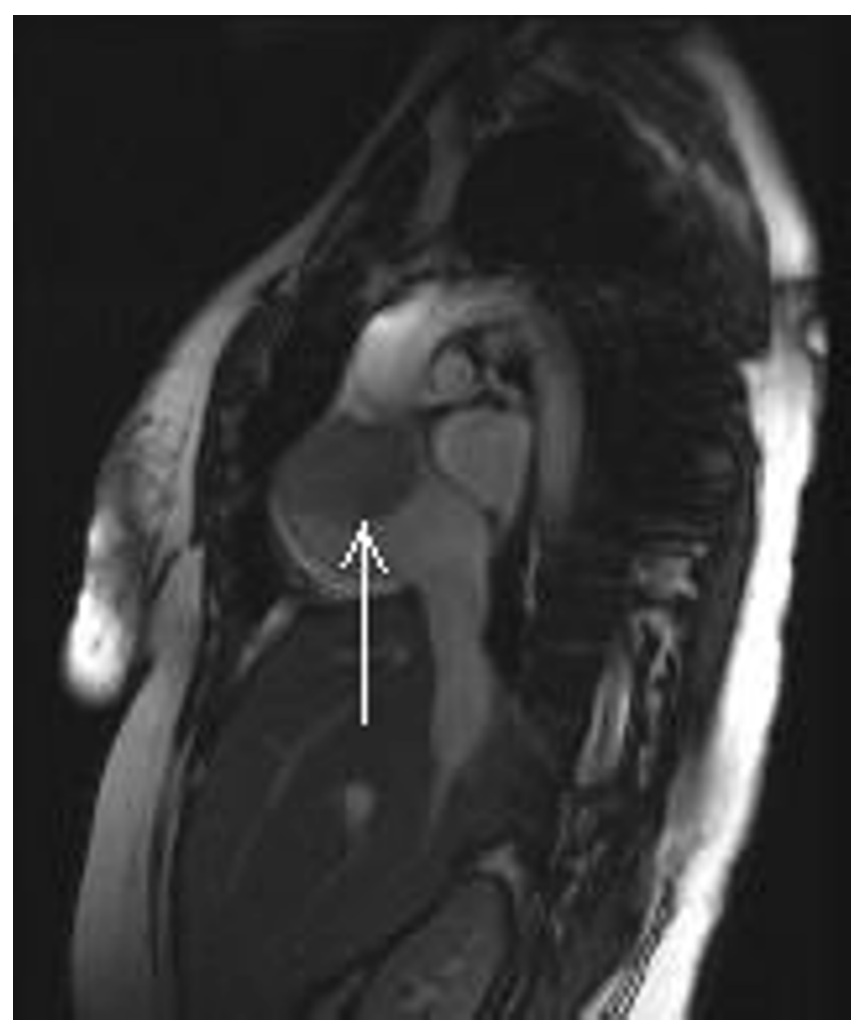

Figure I

MRI of the heart showing low signal density in the right atrial (arrowed) representing metastasis.

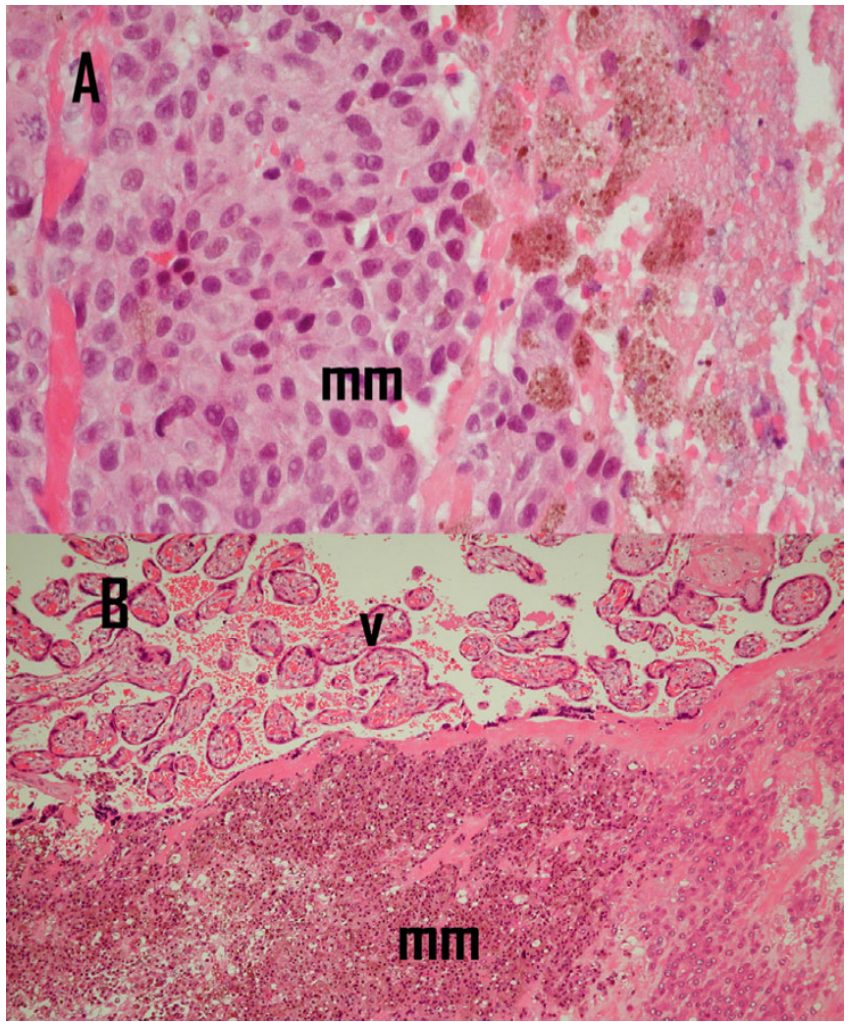

\section{Figure 2}

Histopathology: A. Endomyocardial biopsy showed pleomorphic malignant melanoma $(\mathrm{mm})$ with associated necrosis (original magnification $\times 200$ ). B. Placental tissue shows villous tissue $(\mathrm{v})$ with foci of malignant melanoma $(\mathrm{mm})$ (original magnification $\times 200$ ).

cant problems in the neonatal period. Histological examination of the placental tissue showed unremarkable cord and membranes. The placental bed showed an early third trimester architecture with good villous development. Focally there were groups of viable epitheliod melanocytes, similar to the cardiac tissues with associated thrombus (fig 2B). Immunohistochemistry revealed S100, HMB45 and melan A positivity, consistent with melanoma. As there had been a response on the echocardiogram, we decided to proceed to 8 cycles of dacarbazine chemotherapy. Following this, an MRI scan of the heart showed less tumour bulk with a maximum dimension of less than $2 \times 3 \mathrm{~cm}$. Clinically the patient had no dyspnoea on exertion. The right mandibular lymph gland enlargement was persistent and a selective neck dissection was done. This showed central degeneration in one lymph node with a peripheral rim of fibroconnective tissue showing melanin deposition, representing a response to chemotherapy.

Despite the metastatic nature of her disease, this patient remains well and is currently awaiting opinion for cardiac 
surgery. Her baby is now 10 months old and is free of disease.

\section{Discussion}

Metastatic melanoma of the heart is generally a part of widespread tumour dissemination. The surgical management of these patients varies depending on presence or absence of extracardiac involvement and also the extent of the cardiac tumour. If anatomically feasible, complete resection with reconstruction should be attempted [4]. Indications for complete surgical resection are patients with a preoperative Karnofsky performance status of more than $80 \%$, minimal extracardiac disease, or a deteriorating clinical picture due to cardiac symptoms [4]. In extensive disease, surgical debulking may be considered as a palliative therapeutic option.

Chemotherapy was considered to be the best available option of treatment in this case, considering the risk of a major surgical procedure on the viability of the fetus. There are some previously published reports of the use of chemotherapy for metastatic melanoma in pregnancy. Harkin et al. reported the use of dacarbazine in the $3^{\text {rd }}$ trimester which induced dramatic remission [5]. Another report suggested that combination chemotherapy which included dacarbazine when used in the $2^{\text {nd }}$ trimester did not interfere with the maturation and delivery of the infant [6]. No congenital anomalies in infants born to women treated with dacarbazine have been reported after treatment during the $2^{\text {nd }}$ or $3^{\text {rd }}$ trimester.

Sorafenib an oral targeted agent and a multi-kinase inhibitor, is well tolerated but has little or no anti tumour activity when used alone in advanced melanoma [7]. Ongoing trials in advanced melanoma are evaluating sorafenib in combination therapies. However this agent has not been studied in pregnant women and is not recommended for use in pregnancy.

Placental and fetal metastasis related to cancers have been documented before, the most common being melanoma [8]. The risk of development of melanoma in the fetus with placental involvement is approximately $22 \%$. Babies born with placental metastasis should therefore be considered high risk and monitored closely. Infants developing clinical evidence of maternally derived metastasis have poor prognosis with mortality reaching $100 \%$ and death typically occurring within 3 months of diagnosis [8].

Some difficult ethical issues arise from this case. Firstly, because of poor median survival of 6 months in pregnant women with metastatic melanoma which may make them seriously ill before term, putting the life of the fetus at risk [9]. However, recent reports suggest that there is no signif- icant difference in outcome and survival rate between pregnant and non-pregnant women with melanoma [10]. Secondly, there is an increased risk of melanoma in the infant and when found the prognosis is invariably poor. Maternal factors associated with an unfavourable infant prognosis include maternal age less than 30 years, primiparity, disease onset more than 3 years before current pregnancy, nodal metastasis before pregnancy, more than three sites of metastatic foci during the third trimester, primary site of the leg, and maternal death within 1 month of birth [3]. Counselling of pregnant women who develop metastatic melanoma is vital. The patient and carers need support in their decisions about whether to continue with pregnancy and which treatment options to pursue.

\section{Conclusion}

Metastatic melanoma can sometimes be associated with a good outcome as illustrated in this case. Chemotherapy is a reasonable alternative to surgery when used for disease control in an obstetric setting. A multidisciplinary team approach is vital in management of these complex cases.

\section{Competing interests}

The author(s) declare that they have no competing interests.

\section{Authors' contributions}

PL is primarily responsible for drafting, literature search, submission and revision of the manuscript. SD and $\mathrm{BH}$ are responsible for manuscript editing and advice on literature review. KS is responsible for writing up pathology, providing the slides and manuscript editing. All authors have read and approved the final manuscript.

\section{Acknowledgements}

The patient has kindly consented for the case report to be published.

\section{References}

I. Klatt EC, Heitz DR: Cardiac metastasis. Cancer 1990, 65:1456-1459.

2. Savoia P, Fierro MT, Zaccagna A, Bernengo MG: Metastatic melanoma of the heart. J Surg Oncol 2000, 75:203-207.

3. Baergen RN, Johnson D, Moore T, Benirschke K: Maternal melanoma metastatic to the placenta: a case report and review of literature. Arch Pathol Lab Med I997, I 2 I:508-5 I I.

4. Manner G, Harting MT, Russo P, Gregoric ID, Mukhopadhyay M, Flamm SD, Frazier $\mathrm{OH}$ : Surgical management of metastatic melanoma to the ventricle. Tex Heart Inst J 2003, 30:2 18-220.

5. Beyeler M, Hafner J, Beinder E, Fauchere JC, Stoeckli SJ, Fehr M, Dummer K: Special considerations for stage IV melanoma during pregnancy. Arch Dermatol 2005, I4 I: I077-I079.

6. Dipaola KS, Goodin S, Ratzell M, Florczyk M, Karp G, Ravikumar TS: Chemotherapy for metastatic melanoma during pregnancy. Gynecol Oncol 1997, 66:526-530.

7. Eisen T, Ahmad T, Flaherty KT, Gore M, Kaye S, Marais R, Gibbens I, Hackett $S$, James $M$, Schuchter LM: Sorafenib in advanced melanoma: a Phase II randomised discontinuation trial analysis. Br J Cancer 2006, 95:58I-586.

8. Alexander A, Samlowski WE, Grossman D, Bruggers CS, Harris RM, Zone J, Noyes RD, Bowen GM, Leachman SA: Metastatic melanoma in pregnancy: risk of transplacental metastases in the infant. J Clin Oncol 2003, 2 I:2 179-2186. 
9. Johnston SR, Broadley K, Henson G, Fisher C, Henk M, Gore ME: Management of metastatic melanoma during pregnancy. BMJ 1998, 316:848-849.

10. Silipo V, Simone P, Mariani G, Buccini P, Ferrari A, Catricala C: Malignant melanoma and pregnancy. Melanoma Res 2006, 16:497-500.

Publish with Bio Med Central and every scientist can read your work free of charge

"BioMed Central will be the most significant development for disseminating the results of biomedical research in our lifetime. " Sir Paul Nurse, Cancer Research UK

Your research papers will be:

- available free of charge to the entire biomedical community

- peer reviewed and published immediately upon acceptance

- cited in PubMed and archived on PubMed Central

- yours - you keep the copyright

Submit your manuscript here:

http://www.biomedcentral.com/info/publishing_adv.asp 